\title{
Deposition of Monodisperse Platinum Nanoparticles of Controlled Size on Different Supports
}

\author{
Zinaida Kaidanovych, Yevhen Kalishyn, Peter Strizhak \\ L.V. Pisarzhevsky Institute of Physical Chemistry, The National Academy of Sciences of Ukraine, Kyiv, Ukraine \\ Email: z.kaidanovych@gmail.com, kalishyn.yevhen@gmail.com
}

Received December 18, 2012; revised January 20, 2013; accepted January 30, 2013

\begin{abstract}
Monodisperse platinum nanoparticles with controlled size were synthesized by polyol synthesis and supported on $\gamma-\mathrm{Al}_{2} \mathrm{O}_{3}, \mathrm{SiO}_{2}$ and carbon nanotubes (CNT) by the colloid deposition method. The average size of Pt nanoparticles in colloidal solutions and on supports was determined by TEM images and from XRD patterns. The size of Pt nanoparticles supported on $\mathrm{SiO}_{2}$ and CNT determined from XRD patterns is in a good agreement with size obtained from the TEM analyses. There were shown that no agglomeration and size changing of Pt nanoparticles on these supports were observed. All these findings illustrate that the method of colloid deposition allows one to obtain catalyst with monodisperse platinum nanoparticles of controlled size deposited on different supports without changing the nanoparticle's size and morphology.
\end{abstract}

Keywords: Platinum Nanoparticles; $\mathrm{Pt} / \gamma-\mathrm{Al}_{2} \mathrm{O}_{3} ; \mathrm{Pt} / \mathrm{SiO}_{2}$; Pt/CNT

\section{Introduction}

The pure supported Pt nanoparticles catalysts are of great interest owing to their specific features resulting from their size and morphology that are exploited as efficient catalysts in both homogeneous and heterogeneous catalytic technologies [1,2]. In addition, these have led to investigate the dependence of catalytic activity on the size and shape of Pt nanoparticles as well as the surface-to-volume ratio and quantum size effect because of their potential applications in electronics, catalysis, and biology [1-5]. Performance of Pt nanosized catalysts is affected by numerous factors, one of which is the nature and structure of the support materials. Mostly studies of platinum catalysts have been performed with the metal supported on $\mathrm{SiO}_{2}, \mathrm{Al}_{2} \mathrm{O}_{3}, \mathrm{MgO}$, zeolites, and carbon [1-6]. Materials with supported Pt nanoparticles are known to have good catalytic characteristics. For example, carbon nanotubes (CNT) supported platinum catalyst shows superior activity in catalytic oxidation of various organic compounds $[7,8]$. Also, the electrocatalytic activity of Pt/CNT towards methanol oxidations was discovered [9].

Silica supported nanoparticles have been used to catalyze a wide variety of reactions such as hydrogenations, oxidations, and other organic synthetic reactions. A wide variety of transition metal nanoparticles have also been adsorbed onto $\mathrm{Pt} / \mathrm{SiO}_{2}$ shows selective hydrogenation of acetophenone [10] and high catalytic activity in ethanol electrooxidation [11].
Platinum supported on alumina catalyzes a variety of chemical reactions, particularly, processes used in oil refinery [12]. Cubic platinum nanoparticles supported on alumina have been used to catalyze the NO reduction reaction [13]. It was observed a conversion of the low index facets of the cubic nanoparticles to higher index planes that occurs during the reaction conditions, which is attributed to substantial changes in the catalytic activity and selectivity to reaction products [13]. A large morphological evolution of large platinum nanoparticles is also observed during the NO reduction reaction [14]. Moreover, $\mathrm{Pt} / \gamma-\mathrm{Al}_{2} \mathrm{O}_{3}$ shows catalytic activity in ethylene glycol reforming [15].

Discovery of carbon nanotubes (CNTs), followed by extensive studies of their properties, has also resulted in highlighting their catalytic properties [16-20]. Particularly, comparison of the catalytic activity of metal catalysts supported on various oxides, amorphous carbon, and CNTs showed that catalytic performance is generally better for CNTs. For example, a CNT-supported platinum catalyst shows superior activity in catalytic oxidation of various organic compounds [19].

Many studies show that size- and shape-controlled metallic nanoparticles supported onto mesoporous materials are responsible in changing catalytic activity and selectivity [21-24]. The metal-support interaction, which refers to support-induced changes in reaction selectivity of metal nanoparticles, has been shown mostly on 2-dimensional nanoparticle arrays on oxide substrates, be- 
cause the oxide thin films and corresponding catalysts are easily prepared and characterized providing kinetic differences which invokes different mechanisms [25,26]. However, there are some studies about deposition of colloidal Pt nanoparticles on different supports [27]. There is no information about size changing of nanoparticles after their deposition. A choice of support is vitally important to improve catalytic characteristics, because a nanoparticle-based catalyst can induce reciprocal electronic or chemical interactions.

The goal of this study is to show that the method of deposition from colloid solution gives a reliable root to prepare catalyst with monodisperse Pt nanoparticles with controlled size.

\section{Experimental}

All chemicals and solvent were of the highest purity available and were used as purchased without further purification or distillation.

A solution of $3 \mathrm{~g}$ of Poly(N-vinyl-2-pyrrolidone) (PVP, $\mathrm{Mw}=40,000$ ) and $0.06 \mathrm{~g}$ of sodium hydroxide in $300 \mathrm{ml}$ ethylene glycol were heated to $120^{\circ} \mathrm{C}$ under stirring. Varying amounts (40, 60, 160, 240 and $360 \mathrm{ml}$ ) of 1\% hexachloroplatinic acid in water solution were dosed slowly to the hot ethylene glycol. Next, the solutions were stirred for an additional $30 \mathrm{~min}$ and cooled to room temperature. PVP-protected Pt nanoparticles were precipitated by adding acetone and then redispersed in ethanol.

CNTs were synthesized by the catalytic decomposition of ethylene according to procedure described elsewhere [28]. $\gamma-\mathrm{Al}_{2} \mathrm{O}_{3}$ and $\mathrm{SiO}_{2}$ was grinded and the fraction of $0.25-0.5 \mathrm{~mm}$ was heat-treated at $300^{\circ} \mathrm{C}$ in air. Deposition of Pt nanoparticles on supports was performed by mixing appropriate amounts of $\mathrm{SiO}_{2}, \gamma-\mathrm{Al}_{2} \mathrm{O}_{3}$ or CNTs and colloidal solution of nanoparticles in ethanol under stirring. The obtained samples were dried in air. The obtained samples contained $1.0 \%$ of platinum.

The average particle size was determined from transmission electron spectroscopy (TEM) images. TEM studies were carried out using PEM-125K (Selmi, Ukraine). The samples of colloidal solution of nanoparticles for TEM analysis were dropped onto carbon-coated copper grid. The samples of Pt/support previously were grinded into powder and mixed with drop of water. At least 600 nanoparticles per sample were analyzed to determine their size and distribution.

The samples of $\gamma-\mathrm{Al}_{2} \mathrm{O}_{3}, \mathrm{SiO}_{2}, \mathrm{CNTs}$, and Pt/support were grinded into powder and analyzed using the X-ray diffractometer Bruker D8 Advance. The mean particle size also was determinate using the Scherrer equation:

$$
D=0.9 \lambda /(\beta \cos \theta),
$$

where $\lambda$ is the wavelength used (1.54184 $\AA$ ), $\beta$ is the line broadening at half the maximum intensity in radians and $\theta$ is the angle of diffraction.

\section{Results and Discussion}

Figures 1(a), (c), (e), (g) show a typical TEM images of Pt nanoparticles in colloidal solutions prepared using different amount of hexachloroplatinic acid. Figures 1(b), (d), (f), (h) give corresponding size distributions of Pt nanoparticles. The presented data indicate that the nanoparticles are almost spherical. It was shown that the average size of Pt nanoparticles depends on concentration of hexachloroplatinic acid. If the concentration of hexachloroplatinic acid is $3.3 \mathrm{mmol} / \mathrm{L}$ than the average size of Pt nanoparticles is $1.3 \mathrm{~nm}$ as it is shown in Figure 1(a). The $29.3 \mathrm{mmol} / \mathrm{L}$ of concentration of hexachloroplatinic acid gives $3.1 \mathrm{~nm}$ of Pt nanoparticles. The average size of Pt nanoparticles in colloidal solution increases from 1.3 to $3.1 \mathrm{~nm}$ with increasing of precursor concentration. Corresponding size distribution of Pt nanoparticles is presented in Figures 1(b), (d), (f), (h) showing that size distribution is almost Gaussian. All samples are characterized by narrow width of particle size distribution with typical standard deviations (SD) less than 15\%. Therefore, the synthesized Pt nanoparticles are almost monodispersed.

Pt nanoparticles with average size in colloidal solution $2.8 \mathrm{~nm}$ (Figure 1(e)) were supported on $\gamma-\mathrm{Al}_{2} \mathrm{O}_{3}, \mathrm{SiO}_{2}$ and CNTs in order to determine their size changing after deposition on different supports. Figures 2(a), (c), (e) show typical TEM images of Pt nanoparticles supported on $\gamma-\mathrm{Al}_{2} \mathrm{O}_{3}, \mathrm{SiO}_{2}$ and CNTs. The presented data indicate that supported nanoparticles are not aggregating and stay almost spherical. Figures 2(b)-(f) give corresponding size distributions of supported Pt nanoparticles. The average size of supported Pt nanoparticles is nearly the same as average size of those particles in solution -2.9 $\mathrm{nm}$ for $\mathrm{Pt} / \gamma-\mathrm{Al}_{2} \mathrm{O}_{3}$ and $2.8 \mathrm{~nm}$ for $\mathrm{Pt} / \mathrm{SiO}_{2}$ and $\mathrm{Pt} / \mathrm{CNTs}$. Size distribution of supported Pt nanoparticles is almost gaussian with nearly the same SD as for Pt nanoparticles in solution $0.3-0.4 \mathrm{~nm}$, what is amount less than $15 \%$ of particles size. Therefore, the Pt nanoparticles on these supports stay almost monodispersed as in solution. Comparison of data presented in Figures $\mathbf{1}$ and $\mathbf{2}$ allows one to conclude that deposition of platinum nanoparticles on $\gamma-\mathrm{Al}_{2} \mathrm{O}_{3}, \mathrm{SiO}_{2}$ and CNTs does not produce changing particles size and morphology.

In order to synthesis $\mathrm{Pt} / \gamma-\mathrm{Al}_{2} \mathrm{O}_{3}$ with different size of supported nanoparticles the concentration of hexachloroplatinic acid in reaction solution was varying. The obtained colloidal solutions of Pt nanoparticles with different nanoparticles sizes were deposited on $\gamma-\mathrm{Al}_{2} \mathrm{O}_{3}$. The mean sizes and standard deviations of supported nanoparticles were measured using their TEM images. 


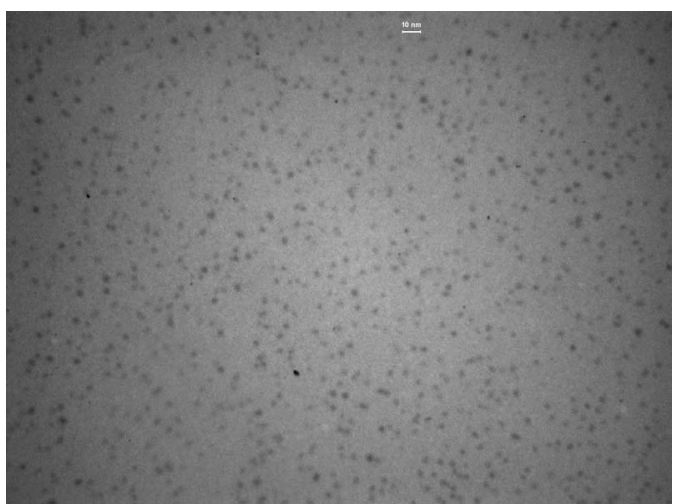

(a)

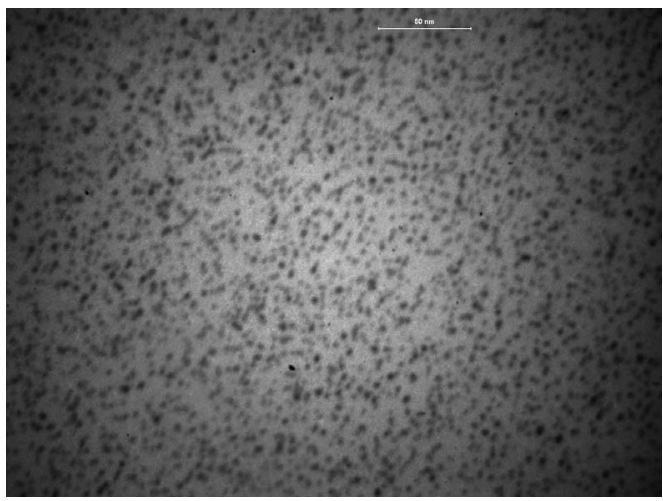

(c)

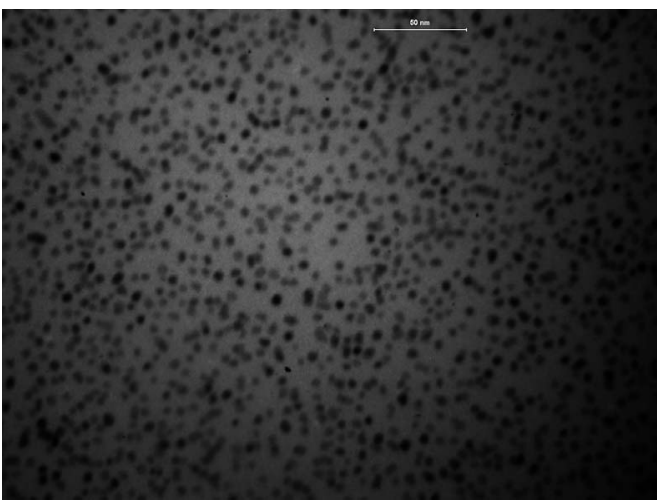

(e)

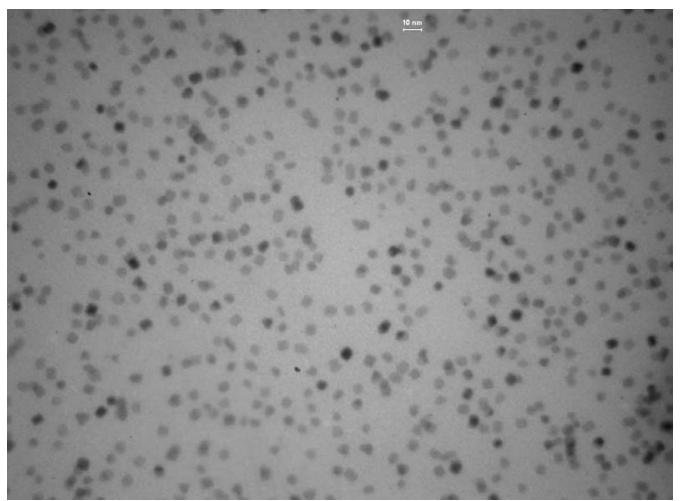

(g)

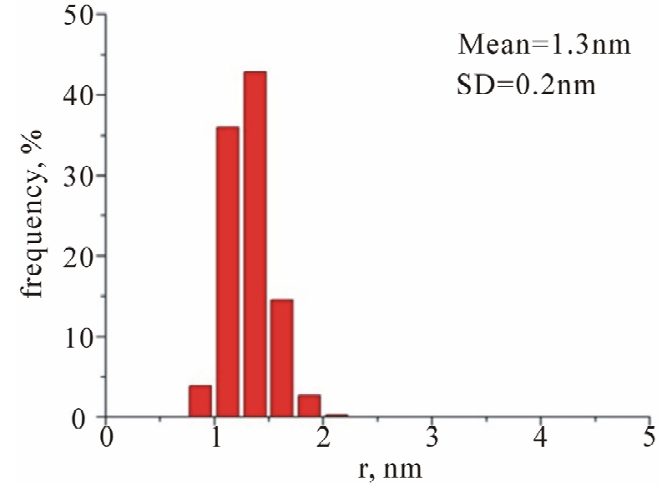

(b)

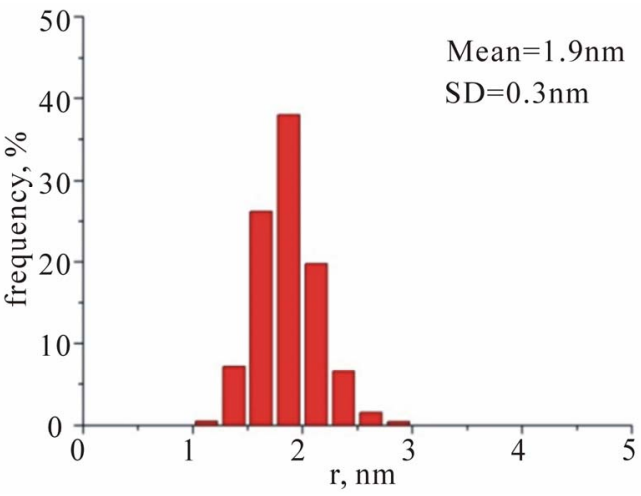

(d)

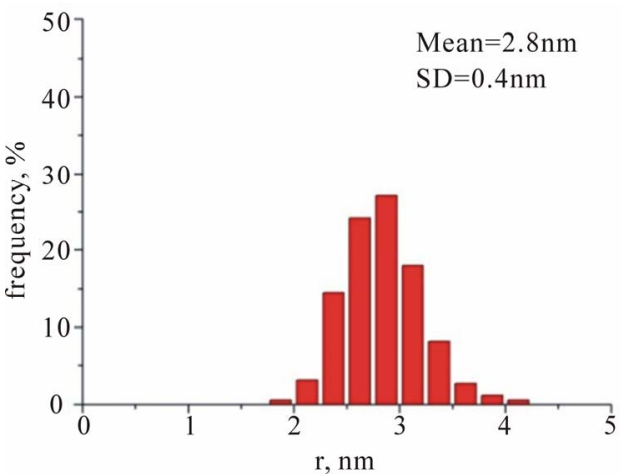

(f)

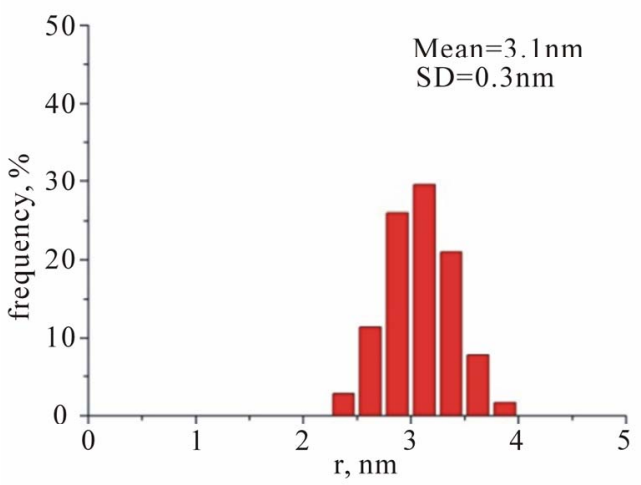

(h)

Figure 1. TEM image of Pt nanoparticles prepared from colloidal solution (a, c, e, g); their distribution by size (b, d, f, h). 


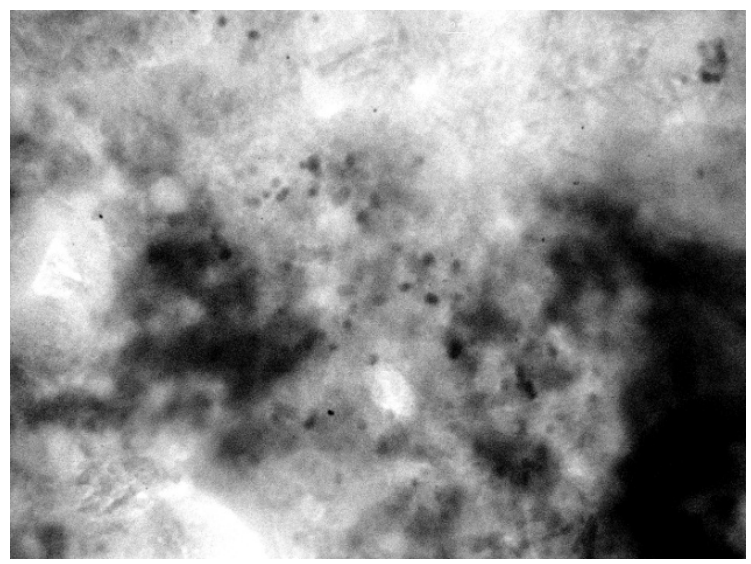

(a)

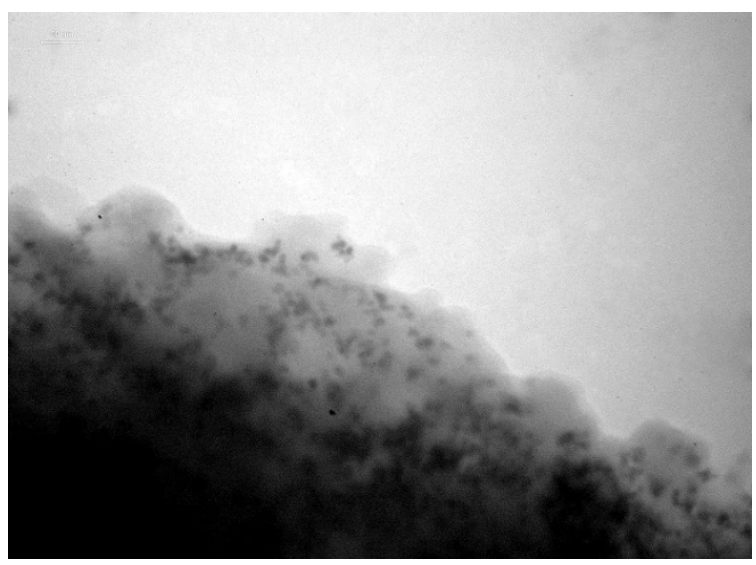

(c)

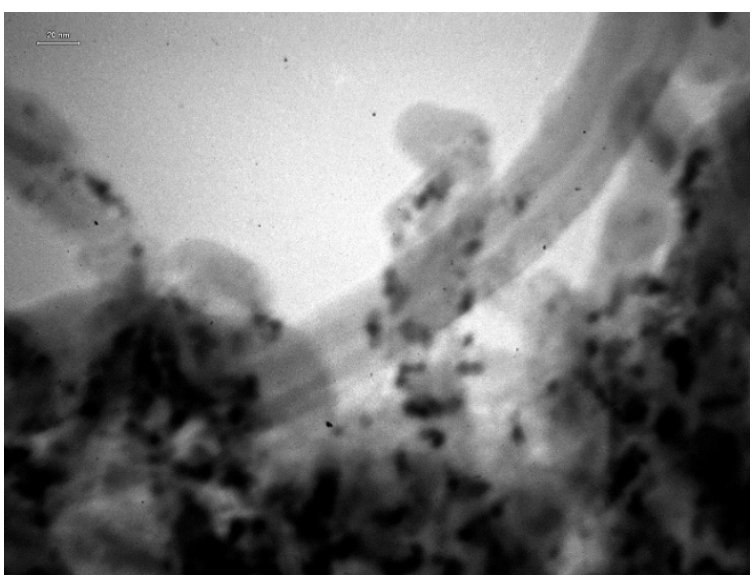

(e)

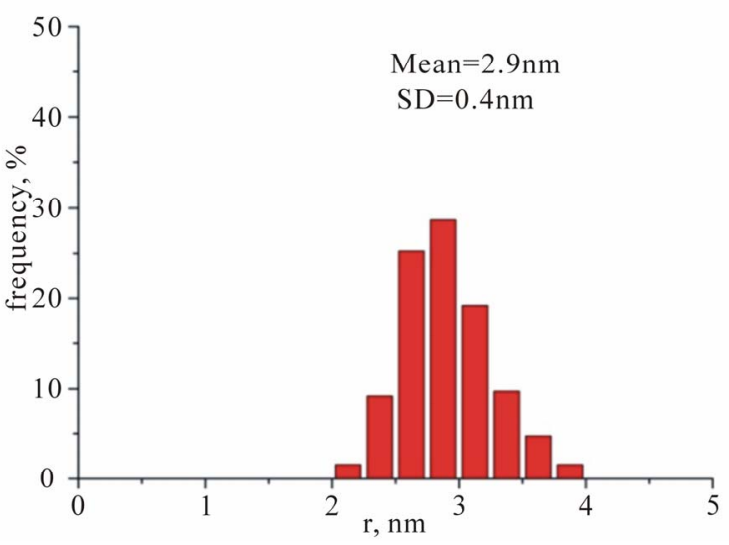

(b)

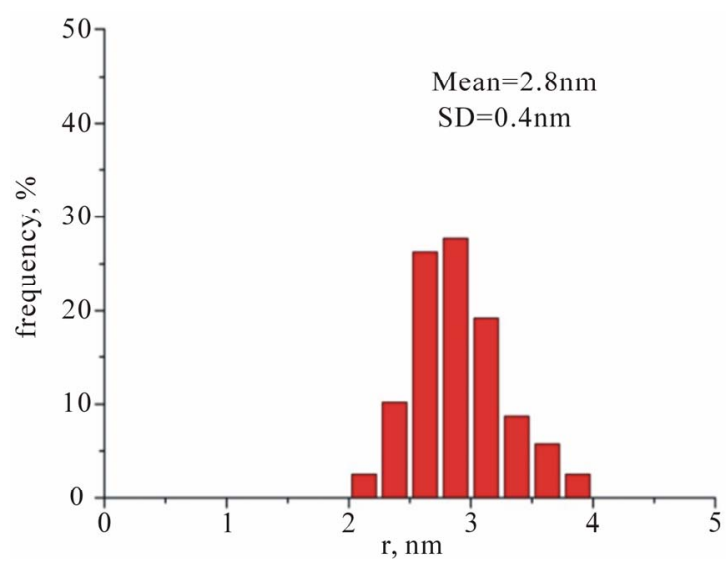

(d)

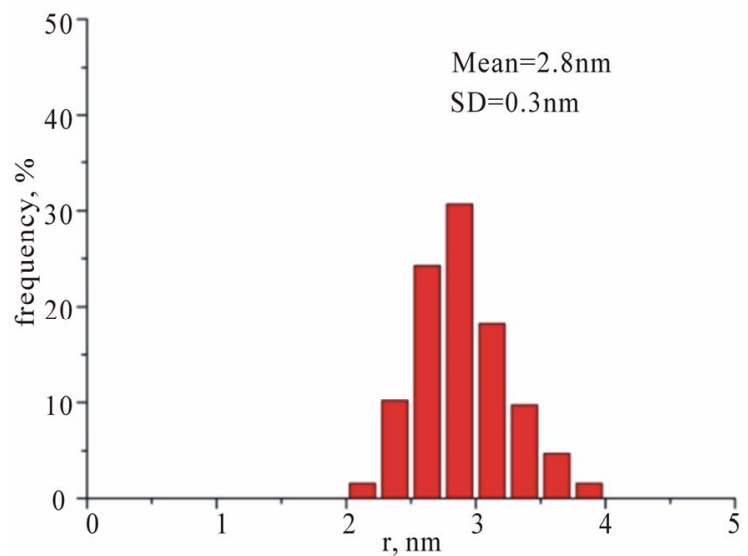

(f)

Figure 2. TEM image of Pt nanoparticles supported on $\gamma-\mathrm{Al}_{2} \mathrm{O}_{3}$ (a), $\mathrm{SiO}_{2}$ (c), CNT (e); their distribution by size (b), (d), (f) respectively.

The obtained dependence presented in Figure 3. The size of supported $\mathrm{Pt}$ nanoparticles increases non linear with increasing the $\mathrm{H}_{2} \mathrm{PtCl}_{6}$ concentration, abruptly at low amount of hexacloroplatinic acid and slightly at higher precursor concentration. It is noticeable that for larger particles the value of standard deviation is bigger, but it is always less than $15 \%$ of mean size of the parti- cles. Varying concentration of hexachloroplatinic acid in reaction solution from 3.3 to $29.3 \mathrm{mmol} / \mathrm{l}$ allows one to obtain $\mathrm{Pt} / \gamma-\mathrm{Al}_{2} \mathrm{O}_{3}$ with average size of nanoparticles in the range of $1.3-3.3 \mathrm{~nm}$.

The XRD patterns were obtained for all solids. Figure 4(a) gives the XRD pattern for $\gamma-\mathrm{Al}_{2} \mathrm{O}_{3}$ and $\mathrm{Pt} / \gamma-\mathrm{Al}_{2} \mathrm{O}_{3}$. The major features of Pt pattern overlaps with that for 


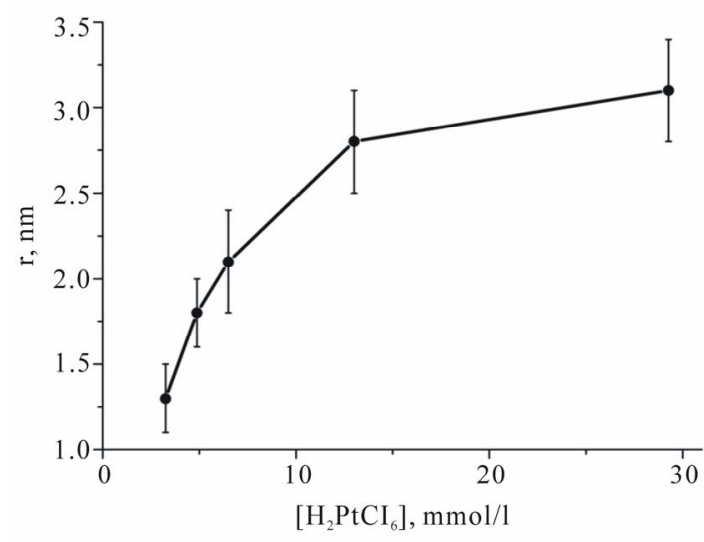

Figure 3. Dependence of average size of Pt nanoparticles supported on $\gamma-\mathrm{Al}_{2} \mathrm{O}_{3}$ on concentration of hexachloroplatinic acid in reaction solution.

$\gamma-\mathrm{Al}_{2} \mathrm{O}_{3}$, that is in agreement with data published in literature [29]. Figure 4(b) shows the XRD patterns for $\mathrm{SiO}_{2}$ and $\mathrm{Pt} / \mathrm{SiO}_{2}$. The XRD pattern for $\mathrm{Pt} / \mathrm{SiO}_{2}$ shows a presence of the crystalline Pt face centered cubic (fcc) phase. The peaks belong to (111), (200), (220) faces corresponding to $2 \theta$ values of about $39.72^{\circ}, 46.08^{\circ}, 67.65^{\circ}$. The XRD peaks of Pt nanoparticles are broad and comparable comparing to those of the bulk Pt material. The most intensive reflection (111) from the Pt nanoparticles were used to calculate the average size of Pt nanocrystallites on the basic of the width of the reflection according to the Debye-Scherrer Equation (1). The crystallite size of Pt particle was estimated about $4 \mathrm{~nm}$, which is in a good agreement with results of TEM analyses.

Figure 4(c) gives the results of XRD analysis of CNT and $\mathrm{Pt} / \mathrm{CNT}$. The results represent the property of the crystalline Pt face centered cubic (fcc) phase. Because of the low concentration of Pt nanoparticles and high intensivity of CNTs reflections it is possible to determine only the most intensive peak (111) of $\mathrm{Pt}$, respective to $2 \theta$ value of about $39.55^{\circ}$. The estimated size of platinum nanoparticles based on the Debye-Scherrer equation was found about $4 \mathrm{~nm}$, that is, again, in a good agreement with results of TEM analyses.

\section{Conclusions}

In this study, nanoparticles with controlled size were synthesized by reducing of hexachloroplatinic acid by ethylene glycol, using PVP as protected agent. These nanoparticles were deposited on $\gamma-\mathrm{Al}_{2} \mathrm{O}_{3}, \mathrm{SiO}_{2}$ and carbon nanotubes by the colloid deposition method. No agglomeration of platinum nanoparticles on all of these supports was observed. The average size determined by TEM images of nanoparticles deposited on different supports corresponds to their size in colloid solution before deposition. Deposition of platinum nanoparticles on

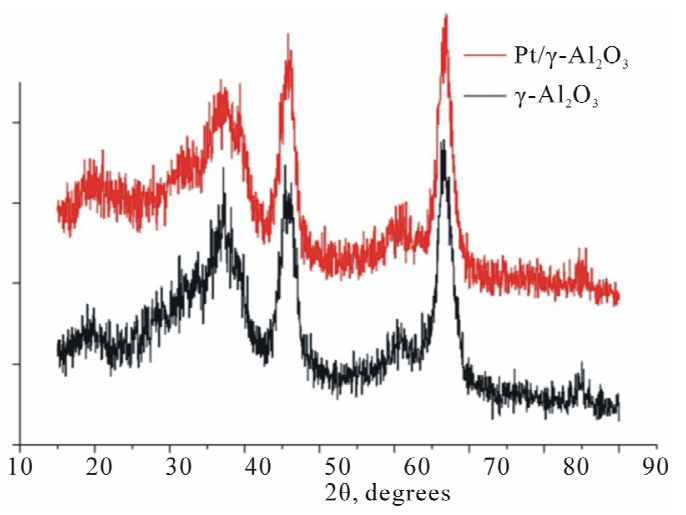

(a)

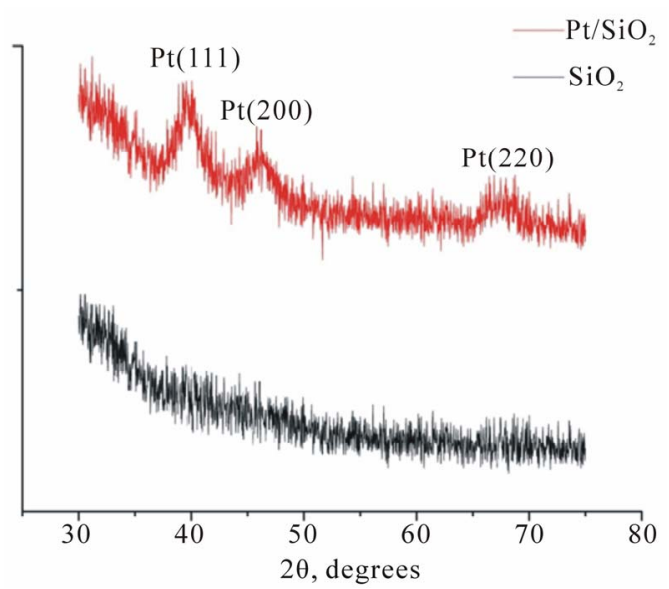

(b)

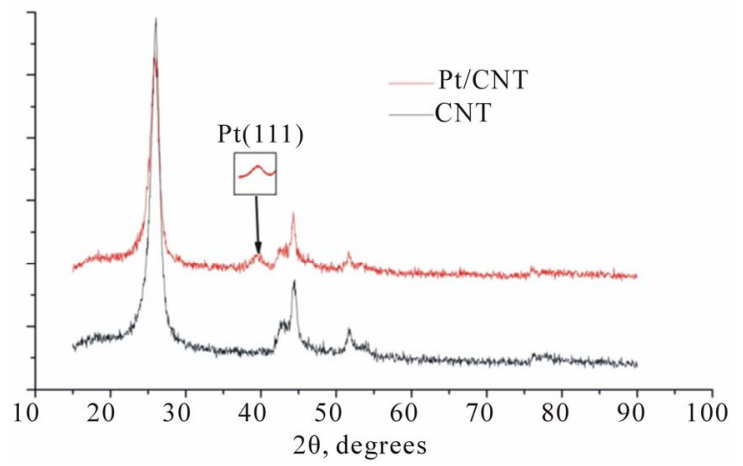

(c)

Figure 4. The XRD patterns of (a) $\gamma-\mathrm{Al}_{2} \mathrm{O}_{3}$ and $\mathrm{Pt} / \gamma-\mathrm{Al}_{2} \mathrm{O}_{3}$; (b) $\mathrm{SiO}_{2}$ and $\mathrm{Pt} / \mathrm{SiO}_{2}$; (c) CNT and $\mathrm{Pt} / \mathrm{CNT}$.

$\gamma-\mathrm{Al}_{2} \mathrm{O}_{3}, \mathrm{SiO}_{2}$ and $\mathrm{CNTs}$ does not lead to changing of particles size and morphology. The varying of concentration of hexachloroplatinic acid in reaction solution allows to obtain $\mathrm{Pt} / \gamma-\mathrm{Al}_{2} \mathrm{O}_{3}$ with controlled size of monodisperse Pt nanoparticles.

According to XRD analysis, supported platinum nanoparticles have the face centered cubic phase. The size of Pt nanoparticles supported on $\mathrm{SiO}_{2}$ and CNT determined from XRD patterns is in a good agreement with size obtained from the TEM analyses. 
Therefore we show that the method of colloid deposition allows one to obtain catalyst with monodisperse platinum nanoparticles of controlled size deposited on different supports without changing the nanoparticle's size and morphology.

\section{Acknowledgements}

The work is supported by the grants of the National Academy of Sciences of Ukraine and the Ministry of Education and Science of Ukraine.

\section{REFERENCES}

[1] Q. Qiang and A. E. Ostafin, "Metal Nanoparticles in Catalysis," Encyclopedia of Nanoscience and Nanotechnology, Vol. 5, 2004, pp. 475-503.

[2] Y. Shao, J. Liu, Y. Wang and Y. Lin, "Novel Catalyst Support Materials for PEM Fuel Cells: Current Status and Future Prospects," Journal of Materials Chemistry, Vol. 19, No. 1, 2009, pp. 46-59. doi:10.1039/b808370c

[3] N. Toshima, H. Yan and Y. Shiraishi, "Recent Progress in Bimetal Nanoparticles: Their Preparation, Structures and Functions," Metal Nanoclusters in Catalysis and Materials Science: The Issue of Size Control, 2008, pp. 49-75.

[4] Z. Peng and H. Yang, "Designer Platinum Nanoparticles: Control of Shape, Composition in Alloy, Nanostructure and Electrocatalytic Property,” Nano Today, Vol. 4, No. 2, 2009, pp. 143-164. doi:10.1016/j.nantod.2008.10.010

[5] N. Tian, Z. Zhou and S. Sun, "Platinum Metal Catalysts of High-Index Surfaces: From Single-Crystal Planes to Electrochemically Shape-Controlled Nanoparticles," Journal of Physical Chemistry C, Vol. 112, No. 50, 2008, pp. 19801-19817. doi:10.1021/jp804051e

[6] J. R. Croy, S. Mostafa, L. Hickman, H. Heinrich and B. R. Cuenya, "Bimetallic Pt-Metal Catalysts for the Decomposition of Methanol: Effect of Secondary Metal on the Oxidation State, Activity, and Selectivity of Pt," Applied Catalysis A, Vol. 350, No. 2, 2008, pp. 207-216. doi:10.1016/j.apcata.2008.08.013

[7] J. Garcia, H. T. Gomes, P. Serp, P. Kalck, J. L. Figueiredo and J. L. Faria, "Platinum Catalysts Supported on MWNT for Catalytic Wet Air Oxidation of Nitrogen Containing Compounds," Catalysis Today, Vol. 102-103, 2005, pp. 101-109. doi:10.1016/j.cattod.2005.02.013

[8] H. T. Gomes, P. Serp, P. Kalck, J. L. Figueiredo and J. L. Faria, "Carbon Nanotubes and Xerogels as Supports of Well-Dispersed Pt Catalysts for Environmental Applications," Applied Catalysis B, Vol. 54, No. 3, 2004, pp. 175-182. doi:10.1016/j.apcatb.2004.06.009

[9] H. Tong, H.-L. Li and X.-G. Zhang, "Ultrasonic Synthesis of Highly Dispersed Pt Nanoparticles Supported on MWCNTs and Their Electrocatalytic Activity towards Methanol Oxidation," Carbon, Vol. 45, No. 12, 2007, pp. 2424-2432. doi:10.1016/j.carbon.2007.06.028

[10] C.-S. Chen, H.-W. Chen and W.-H. Cheng, "Study of Selective Hydrogenation of Acetophenone on $\mathrm{Pt} / \mathrm{SiO}_{2}$," $A p$ plied Catalysis A: General, Vol. 248, No. 1-2, 2003, pp.

\section{7-128. doi:10.1016/S0926-860X(03)00156-X}

[11] B. Liu, J. H. Chen, X. X. Zhong, K. Z. Cui, H. H. Zhou and Y. F. Kuang, "Preparation and Electrocatalytic Properties of Pt-SiO ${ }_{2}$ Nanocatalysts for Ethanol Electrooxidation,” Journal of Colloid and Interface Science, Vol. 307, No. 1, 2007, pp. 139-144. doi:10.1016/j.jcis.2006.11.027

[12] I. V. Babich and J. A. Moulijn, "Science and Technology of Novel Processes for Deep Desulfurization of Oil Refinery Streams: A Review,” Fuel, Vol. 82, No. 6, 2003, pp. 607-631. doi:10.1016/S0016-2361(02)00324-1

[13] I. Balint, A. Miyazaki and K. Aika, "Effect of Platinum Morphology on Lean Reduction of NO with $\mathrm{C}_{3} \mathrm{H}_{6}$," Physical Chemistry Chemical Physics, Vol. 6, No. 8, 2004, pp. 2000-2001. doi:10.1039/b402971b

[14] I. Balint, A. Miyazaki and K. Aika, "Investigation of the Morphology-Catalytic Reactivity Relationship for Pt Nanoparticles Supported on Alumina by Using the Reduction of NO with $\mathrm{CH}_{4}$ as a Model Reaction,” Chemical Communications, No. 10, 2002, pp. 1044-1045. doi:10.1039/b202421g

[15] X. H. Liu, Y. Guo, W. J. Xu, Y. Q. Wang, X. Q. Gong, Y. L. Guo, Y. Guo and G. Z. Lu, "Catalytic Properties of $\mathrm{Pt} / \mathrm{Al}_{2} \mathrm{O}_{3}$ Catalysts in the Aqueous-Phase Reforming of Ethylene Glycol: Effect of the Alumina Support,” Kinetics and Catalysis, Vol. 52, No. 6, 2011, pp. 817-822. doi:10.1134/S0023158411060115

[16] P. Serp, M. Corrias and P. Kalck, "Carbon Nanotubes and Nanofibers in Catalysis," Applied Catalysis A, Vol. 253, No. 2, 2003, pp. 337-358. doi:10.1016/S0926-860X(03)00549-0

[17] H. Marsh, E. A. Heintz and F. Rodriquez-Reinoso, "Introduction to Carbon Technologies,” Alicante, 1997.

[18] F. Rodriguez-Reinoso, "The Role of Carbon Materials in Heterogeneous Catalysis,” Carbon, Vol. 36, No. 3, 1998, pp. 159-318. doi:10.1016/S0008-6223(97)00173-5

[19] H. T. Gomes, P. Serp, P. Kalck, J. L. Figueiredo and J. L. Faria, "Carbon Nanotubes and Xerogels as Supports of Well-Dispersed Pt Catalysts for Environmental Applications," Applied Catalysis B, Vol. 54, No. 3, 2004, pp. 175-182. doi:10.1016/j.apcatb.2004.06.009

[20] B. Rajesh, K. Ravindranathan Thampi, J. M. Bonard, N. X. Xanthopoulos, H. J. Mathieu and B. Viswanathan, “Carbon Nanotubes Generated from Template Carbonization of Polyphenyl Acetylene as the Support for Electrooxidation of Methanol," Journal of Physical Chemistry $B$, Vol. 107, No. 12, 2003, pp. 2701-2708. doi:10.1021/jp0219350

[21] I. Lee, F. Delbecq, R. Morales, M. A. Albiter and F. Zaera, "Tuning Selectivity in Catalysis by Controlling Particle Shape," Nature Materials, Vol. 8, No. 2, 2009, pp. 132-138. doi:10.1038/nmat2371

[22] I. Lee, R. Morales, M. A. Albiter and F. Zaera, “Synthesis of Heterogeneous Catalysts with Well Shaped Platinum Particles to Control Reaction Selectivity," Proceedings of the National Academy of Sciences of the United States of America, Vol. 105, No. 40, 2008, pp. 15241-15246. doi:10.1073/pnas.0805691105

[23] K. M. Bratlie, H. Lee, K. Komvopoulos, P. Yang and G. A. Somorjai, "Platinum Nanoparticle Shape Effects on 
Benzene Hydrogenation Selectivity," Nano Letters, Vol. 7, No. 10, 2007, pp. 3097-3101. doi:10.1021/nl0716000

[24] S. Alayoglu, C. Aliaga, C. Sprung and G. A. Somorjai, "Size and Shape Dependence on Pt Nanoparticles for the Methylcyclopentane/Hydrogen Ring Opening/Ring Enlargement Reaction,” Catalysis Letters, Vol. 141, No. 7, 2011, pp. 914-924. doi:10.1007/s10562-011-0647-6

[25] A. B. Boffa, C. Lin, A. T. Bell and G. A. Somorjai, "Lewis Acidity as an Explanation for Oxide Promotion of Metals: Implications of Its Importance and Limits for Catalytic Reactions,” Catalysis Letters, Vol. 27, No. 3-4, 1994, pp. 243-249. doi:10.1007/BF00813909

[26] A. Bruix, J. A. Rodriguez, P. J. Ramirez, S. D. Senanayake, J. Evans, J. B. Park, D. Stacchiola, P. Liu, J. Hrbek and F. Illas, "Catalyst-Support Interactions: Electronic Perturbations,” Journal of American Chemical Society, Vol. 134, No. 48, 2012, pp. 8968-8974. doi:10.1021/ja302070k
[27] A. Kwangjin, N. Musselwhite, G. Kennedy, V. Pushkarev, L. R. Baker and G. A. Somorjai, "Preparation of Mesoporous Oxides and Their Support Effects on Pt Nanoparticle Catalysts in Catalytic Hydrogenation of Furfural," Journal of Colloid and Interface Science, Vol. 392, 2013, pp. 122-128. doi:10.1016/j.jcis.2012.10.029

[28] A. I. Tripol'skii, N. V. Lemesh, V. O. Khavrus' and P. E. Strizhak, "Morphology of Carbon Nanotubes, Obtained by Decomposition of Ethylene on Nickel Nanoparticles at Various Rates of Flow and Concentration of $\mathrm{C}_{2} \mathrm{H}_{2}$," Theoretical and Experimental Chemistry, Vol. 44, No. 4, 2008, pp. 240-244. doi:10.1007/s11237-008-9034-9

[29] D. S. Brandão, R. M. Galvão, M. da Graça, M. C. da Rocha, P. Bargiela and E. A. Sales, "Pt and Pd Catalysts Supported on $\mathrm{Al}_{2} \mathrm{O}_{3}$ Modified with Rare Earth Oxides in the Hydrogenation of Tetralin, in the Presence of Thiophene," Catalysis Today, Vol. 133-135, 2008, pp. 324330. doi:10.1016/j.cattod.2007.12.128 